\title{
Optimal Overcurrent Relay Coordination Using Hybrid Genetic Algorithm and Linear Programming Method
}

\author{
[Hasan Can Kılıçkıran, İbrahim Şengör, Hüseyin Akdemir, Bedri Kekezoğlu]
}

\begin{abstract}
Power systems are exposed to various faults, such as phase-phase, phase-ground, 3-phase-ground during their operations. Due to fault type and location, some part of the system cannot be supplied when a fault occurs. Moreover, this issue not only reduces power quality parameters but also increases total energy cost of the system. Overcurrent relays are widely used tools for detecting and clearing fault in power systems. In addition to this, relays must be operated in a harmony whilst fault occurs. The coordination among relays can be quarantined by arranging their characteristics through adjusting their parameters. In conventional approach, operation characteristics of relays depend on two variables namely, pick up current (Ip) and time multiplier settings (TMS). In recent decades, several studies about optimization of relay coordination problem have been done. Since relay coordination problem is a non-convex optimization problem, most of studies has been used heuristic optimization techniques such as Particle Swarm Optimization (PSO), Genetic Algorithm (GA), Ant Colony Optimization (ACO). In this paper, relay coordination problem is solved by a hybrid Genetic Algorithm and Linear Programming (GALP) method. Both GA search space and computational effort is reduced using GALP. Hybrid method is tested on IEEE 14-Bus Test System. GALP and GA is programmed in MATLAB while DigSILENT Power Factory program is used to obtain values of power system parameters. Results show that GALP can converge to optimal solution faster than GA and increase in Distributed Generation (DG) capacity causes a rise in the total relay operating time.
\end{abstract}

Keywords - relay coordination, power systems, optimization, genetic algorithm, linear programming, hybrid, distributed generation

\section{Introduction}

Power systems are designed for supplying electrical energy from electric power plants to the end-users in a reliable and secure way [1]. However, some part of power systems can be interrupted by system faults that occur due to natural causes, unexpected load variations or equipment breakdowns [2]. Relays are most commonly used power system equipment in order to clear faulted part and to bring the system back into normal operating conditions as quickly as possible. Among relay types, directional overcurrent relays (DOCRs) are widely preferred type of overcurrent relays because of their low cost.

Hasan Can Kılıçkıran, İbrahim Şengör, Hüseyin Akdemir, Bedri Kekezoğlu

Yildiz Technical University

Turkey
A key aspect of power system protection is relay coordination. Therefore, in recent decades there has been an increasing interest in optimal relay coordination problem. The main purpose of relay coordination optimization problem is to minimize relay operating time while ensuring coordination of relays in case of system faults [3]. The problem is fundamentally depends on two DOCRs settings, namely pickup current setting $\left(I_{p}\right)$ and time multiplier setting (TMS). Linear programming or nonlinear programming are the two ways that are used to formulate optimal relay coordination problem [4]. In linear approach $I_{p}$ settings are assumed to be pre-determined and the rest of the problem is solved using linear programming (LP) technique. A considerable amount of papers has been published that evaluates optimal relay coordination as a linear programming problem [5]-[9]. On the other hand, two settings are considered as continuous variables in nonlinear approach and problem is solved using nonlinear programming (NLP) technique [15]. Much of current literature on optimal relay coordination problem pays particular attention on population based methods. Genetic Algorithm (GA) [10], Particle Swarm Optimization (PSO) [11] and Evolutionary Algorithm (EA) [12] are the most popular ones with researches. The main advantages of such techniques are the convergence of the global optimal solution accurately. In addition to abovementioned methods, several hybrid methods are developed in recent years. Hybrid Genetic Algorithm and Linear Programming (GALP) and Genetic Algorithm and Non-Linear Programming (GANLP) are the most promising ones among these methods.

In this paper, hybrid GALP method is used for solving relay coordination problem of 14-Bus IEEE power system. For this purpose 14-Bus IEEE power system is simulated in DigSILENT/PowerFactory software. Based on load-flow and short-circuit calculations of system, optimal relay settings is determined by hybrid GALP algorithm. Additionally, Distributed Generation (DG) effect on relay coordination is investigated by connecting DGs with different size to the power system.

The rest of paper is organized as follows: Second section explains formulation of relay coordination problem. Third section presents GALP method. Sequentially, fourth section gives details about studied power system. Finally, simulation results are presented in section five and section six concludes the paper. 


\section{Problem Formulation}

The main objective of optimal relay coordination problem is to operate the relays in minimum time while ensuring coordination between relays. The objective function is defined as follows [13]:

$$
\min \sum_{\mathrm{j}=1}^{\mathrm{M}} \sum_{\mathrm{i}=1}^{\mathrm{N}} \mathrm{t}_{\mathrm{ij}}
$$

where $t$ is the operating time of relay, $i$ is relay number, $j$ is faulted location, $N$ and $M$ are total relay number and total fault number that are considered, respectively [14]. While objective function is minimized following constraints do not be exceed.

\section{A. Relay Characteristics}

Several different examples that is used to calculate relay characteristics can be found in the literature. In this paper, inverse time characteristic specified in IEC standards is used. Characteristic function of DOCRs is given in (2). All relays are assumed to be identical and operated by standard identical characteristic [15].

$$
\mathrm{t}=\frac{0.14 x \text { TMS }}{\left(\frac{\mathrm{I}_{\mathrm{i}}}{\mathrm{I}_{\mathrm{i}}}\right)^{0.02}-1}
$$

In (2), $\mathrm{t}$ is relay operating time, TMS and Iset is time multiplier and pickup current settings respectively while Ii is short circuit current that is flowing through seconder winding of current transformer of relay.

\section{B. Constraints of Relay Settings}

Relay setting parameters inherently have borders that constraint relay operating time directly. In order to keep relay parameter in their practical limits, following constraint is used while constructing optimization problem.

$$
\begin{gathered}
\mathrm{TMS}_{\min } \leq \mathrm{TMS} \leq \mathrm{TMS}_{\max } \\
\mathrm{I}_{\mathrm{p}_{\min }} \leq \mathrm{I}_{\mathrm{p}} \leq \mathrm{I}_{\mathrm{p}_{\max }}
\end{gathered}
$$

In Inequality (3), TMS limits are determined through permissible range given by relay manufacturer. In this paper TMS range is assumed to be between 0.05-1.2. Similarly, $I_{p}$ parameter is determined based on relay upper and lower bounds. Moreover, maximum load current and minimum short circuit current that are flowing through relay have to be considering to avoid unintended operations.

\section{Coordination Constraints}

Relays are always operated with their back-up pairs in power systems in order to guarantee proper operation in case of system faults. Therefore, when a relay is assigned to operate against a particular fault, another relay is also assigned with a delay for the same fault. The term "Coordination Time Interval (CTI)" is used to refer this delaying period and usually taken as 0.3 .

$$
\mathrm{t}_{\mathrm{b}}^{\mathrm{F}}-\mathrm{t}_{\mathrm{p}}^{\mathrm{F}} \leq \mathrm{CTI}
$$

In Equation (5), $t_{b}$ and $t_{p}$ are indicate back-up and primary relay operation time against a near-end fault respectively. This condition must be met for all faults that can be occurred in power system.

\section{Hybrid GA and LP Method}

The main purpose in this method is to decompose the optimization problem into two sub-problems. First subproblem is solved using GA while the second part with LP. By evaluating problem in two steps computational efficiency is increased. The flowchart of the algorithm can be seen from Fig. 1. In the first step, GA is implemented in order to determine Ip values. The GA process is continued until all randomly created Ip values are obtained. Then, problem turns into a linear problem with known Ip values and unknown TMS values. Once the linear problem obtained, LP solver is used and optimal TMS values are determined, and LP phase ends. The LP solver function is called as many as total chromosome number in one iteration. Afterwards, algorithm returns to GA process and continues from where it breaks. Equation (2) is used to calculate fitness of chromosomes. If there is any chromosome with TMS or Ip values out of limits, penalty value is added to its fitness function and possibility of being in next generation for this 
Proc. of the Fourth International Conference on Advances in Computing, Electronics and Communication - ACEC 2016.

Copyright (c) Institute of Research Engineers and Doctors. All rights reserved.

ISBN: 978-1-63248-113-9 doi: 10.15224/ 978-1-63248-113-9-48

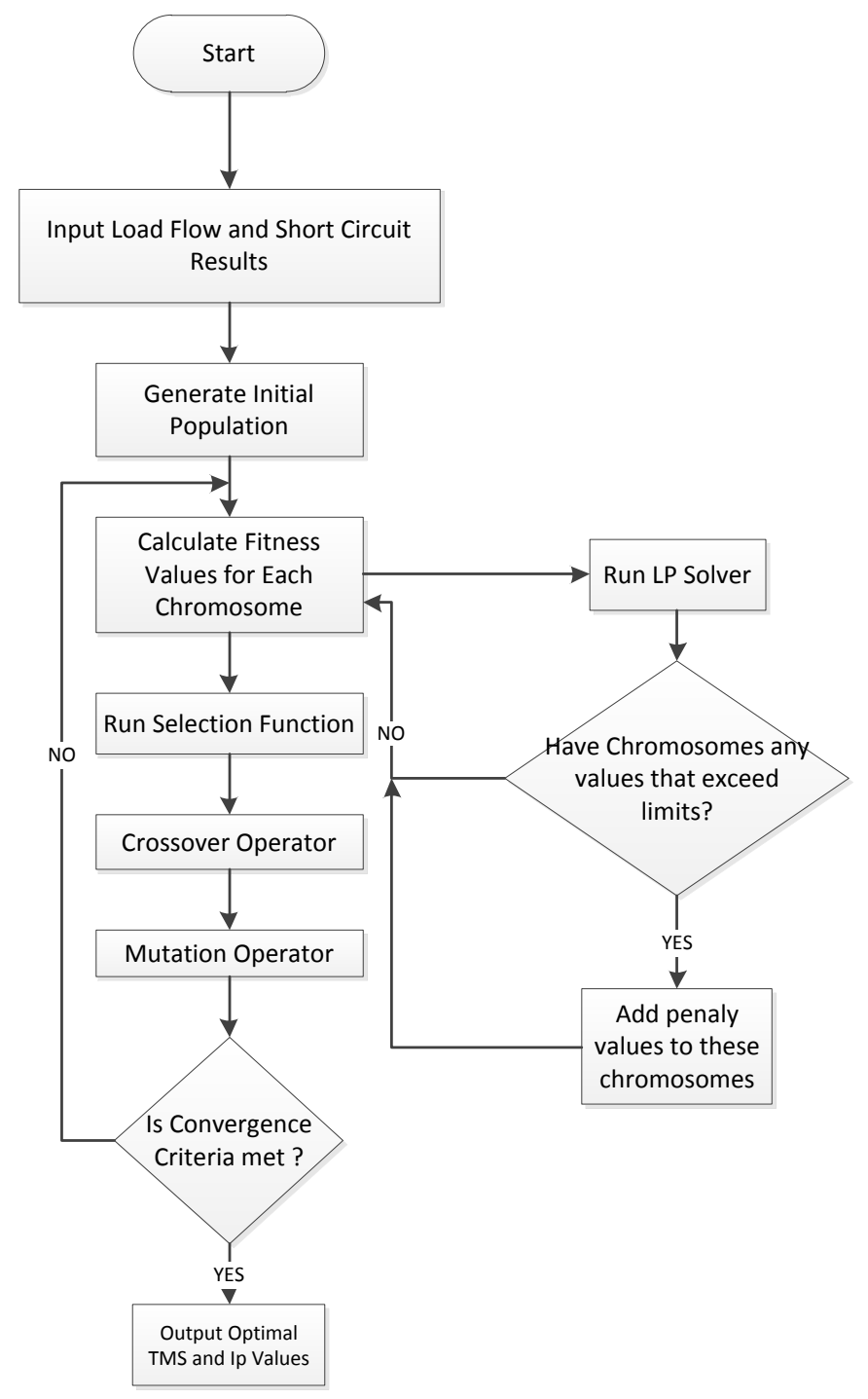

Figure 1. Flowchart of Hybrid GA-LP

chromosome is decreased. At the end of this process, optimal relay settings are determined.

\section{Studied Power System}

In this study, IEEE 14-bus power system is used. Onephase layout of power system is given in Fig. 2 and system details can be found in [16]. System comprises five synchronous machines. Three of these machines are used as synchronous compensators which gives pure reactive power to the system, while the rest of generators are used both active and reactive power sources. The system contains 11 loads and total desired load values are 259 MW and 81.3 MVAr.

It is assumed that the test system under study has 19 Directional Over-Current Relay (DOCR) in the $132 \mathrm{kV}$ side. Besides, faults are considered as they occur in the middle of each line. Both relay short-circuit currents and primary-backup relay pairs are assigned according to this short-circuit calculations. Also, three different DGs are connected to the system of which sizes 12 MVA, 24 MVA, and 24 MVA. The connections are carried out through bus 10, 12, and 14, respectively.

\section{Simulation Results}

In order to analyze the DG effect on relay coordination and to compare GA and GALP methods, four different cases are evaluated in this paper. Initially, it is assumed that system contains no DG. Afterwards, 12 MVA DG is connected to Bus 10. Consecutively, 24 MVA DG is integrated to Bus 12 while keeping the first DG is connected and DG size is increased to 36 MVA. Lastly, another 24 MVA DG is added via Bus 14 and total connected DG size is reached 60 MVA. On the other hand, relay coordination problem is solved using GA and GALP for these four different cases.

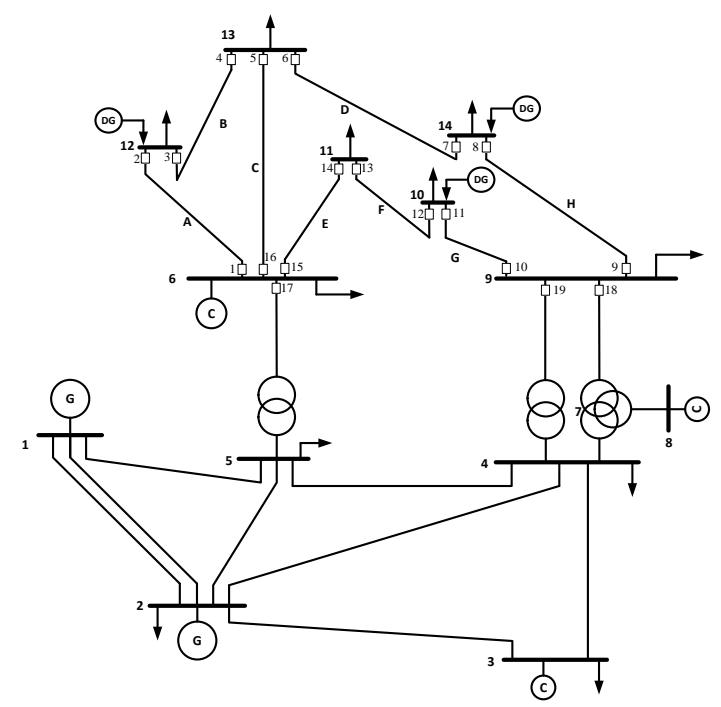

Figure 2. IEEE 14-Bus Test System

Table 1 summarizes DG sizes, total operating time of last population, operating time of best individual in last population, and iteration number that algorithm is converged to an optimal solution. It can be seen from Table 1 that when integrated DG size increase operating time of all relay in the system is increased independently of method. However, increase in DG size has not any clear effect on number of iteration that algorithm converged. Another important result from Table 1 is the difference in the number of iterations between GA and GALP methods. In first case, GALP method is converged 189 iterations before GA. Additionally, this difference is 97, 151, and 106 in second, third, and fourth cases respectively. Also, total operating time of last population values show that GALP method led to a population with more suitable individual than GA. 
Proc. of the Fourth International Conference on Advances in Computing, Electronics and Communication - ACEC 2016. Copyright (C) Institute of Research Engineers and Doctors. All rights reserved.

ISBN: 978-1-63248-113-9 doi: 10.15224/ 978-1-63248-113-9-48

TABLE 1. OPERATING TIMES and CONVERGED ITERATION NUMBERS

\begin{tabular}{|c|c|c|c|c|c|c|}
\hline \multirow{2}{*}{$\begin{array}{l}\text { Connec- } \\
\text { ted DG } \\
\text { Size }\end{array}$} & \multicolumn{2}{|c|}{$\begin{array}{l}\text { Total Operating } \\
\text { Time of Last } \\
\text { Population }\end{array}$} & \multicolumn{2}{|c|}{$\begin{array}{l}\text { Operating Time of } \\
\text { Best Individual }\end{array}$} & \multicolumn{2}{|c|}{$\begin{array}{c}\text { Converged } \\
\text { Iteration Number }\end{array}$} \\
\hline & GA & GALP & GA & GALP & GA & GALP \\
\hline No DG & 22812 & 20255 & 19,02 & 19,28 & 223 & 34 \\
\hline 12 MVA & 26541 & 22474 & 22,54 & 22,18 & 145 & 48 \\
\hline 36 MVA & 28171 & 23787 & 23,01 & 22,76 & 193 & 42 \\
\hline 60 MVA & 30354 & 24199 & 23,38 & 23,074 & 150 & 44 \\
\hline
\end{tabular}

\section{Conclusion}

In this paper, the DG effect on DOCR coordination is investigated. For this purpose, IEEE 14-Bus Test System is modelled in DIgSILENT/PowerFactory software and problem is solved based on load and short circuit currents. Two different method namely, GA and GALP, is implemented to optimal relay coordination problem. As a result, total operating time of relays is increased when total connected DG capacity increase. Additionally, GALP method is converged to optimal solution faster than GA. Moreover, last population obtained by GALP includes more proper individuals compared to GA. Mitigating the negative DG effect on relay coordination problem is considered as future work.

\section{References}

[1] A. G. Phadke and J. S. Thorp, Computer Relaying for Power Systems. 2009.

[2] S. H. Horowitz, RELAYING Third Edition. 2008.

[3] A. J. Urdaneta, R. Nadira, and L. G. Pérez Jiménez, "Optimal Coordination of Directional Overcurrent Relays in Interconnected Power Systems," IEEE Trans. Power Deliv., vol. 3, no. 3, pp. 903-911, 1988.

[4] T. Amraee, "Coordination of directional overcurrent relays using seeker algorithm," IEEE Trans. Power Deliv., vol. 27, no. 3, pp. 1415-1422, 2012.

[5] H. K. Karegar, H. A. Abyaneh, V. Ohis, and M. Meshkin, "Preprocessing of the optimal coordination of overcurrent relays," Electr. Power Syst. Res., vol. 75, no. 2-3, pp. 134-141, 2005.

[6] A. J. Urdaneta, L. G. Pérez, J. F. Gómez, B. Feijoo, and M. González, "Presolve analysis and interior point solutions of the linear programming coordination problem of directional overcurrent relays," Int. J. Electr. Power Energy Syst., vol. 23, no. 8, pp. 819-825, 2001.

[7] J. Urdaneta, L. G. Pérez, and H. Restrepo, "Optimal coordination of directional overcurrent relays considering dynamic changes in the network topology," IEEE Trans. Power Deliv., vol. 12, no. 4, pp. 14581464, 1997.

[8] B. Chattopadhyay, M. S. Sachdev, and T. S. Sidhu, "An on-line relay coordination algorithm for adaptive protection using linear programming technique," IEEE Trans. Power Deliv., vol. 11, no. 1, pp. 165-173, 1996.

[9] S. Ralhan and S. Ray, "Directional overcurrent relays coordination using linear programming intervals: A comparative analysis," 2013 Аппи. IEEE India Conf. INDICON 2013, 2013.

[10] C. A. Castillo Salazar, A. Conde Enríquez, and S. E. Schaeffer, "Directional overcurrent relay coordination considering nonstandardized time curves," Electr. Power Syst. Res., vol. 122, pp. 42-49, 2015.
[11] A. Srivastava, J. M. Tripathi, S. R. Mohanty, and B. Panda, "Optimal over-current relay coordination with distributed generation using hybrid particle swarm optimization-gravitational search algorithm," Electr. Power Components Syst., vol. 44, no. 5, 2016.

[12] M. Y. Shih, A. Conde Enríquez, T.-Y. Hsiao, and L. M. Torres Treviño, "Enhanced differential evolution algorithm for coordination of directional overcurrent relays," Electr. Power Syst. Res., vol. 143, 2017.

[13] P. P. Bedekar and S. R. Bhide, "Optimum coordination of directional overcurrent relays using the hybrid GA-NLP approach," IEEE Trans. Power Deliv., vol. 26, no. 1, pp. 109-119, 2011.

[14] H. H. Zeineldin, E. F. El-Saadany, and M. M. A. Salama, "Optimal coordination of overcurrent relays using a modified particle swarm optimization," Electr. Power Syst. Res., vol. 76, no. 11, pp. 988-995, 2006.

[15] H. M. Sharaf, H. H. Zeineldin, D. K. Ibrahim, and E. E. D. A. El-Zahab, "A proposed coordination strategy for meshed distribution systems with DG considering user-defined characteristics of directional inverse time overcurrent relays," Int. J. Electr. Power Energy Syst., vol. 65, pp. 4958,2015 .

[16] Univ. Washington. Seattle, WA, Oct. 2016 [Online]. Available: http://www.ee.washington.edu/research/pstca/

About Author (s):

\begin{tabular}{|l|l|}
\hline Hasan Can KILICKIRAN was born in Istanbul, \\
Turkey. He completed B.Sc. at the Department of \\
Electrical Engineering and M.Sc. at same \\
department of Yildiz Technical University \\
respectively in 2011 and 2014. He is currently \\
working as a Research Assistant at the Electrical \\
Engineering Department of Yildiz Technical \\
University, Turkey while pursuing his Ph. D \\
studies. His research interests are Protection of \\
Power Systems and Integration of Wind Energy \\
to Power Systems. \\
Ibrahim Sengor was born in Manisa, Turkey. He \\
completed B.Sc. at the Department of Electrical \\
Engineering, Istanbul Technical University and \\
M.Sc. at same department of Yildiz Technical \\
University respectively in 2013 and 2016. He is \\
currently working as a Research Assistant at the \\
Electrical Engineering Department of Yildiz \\
Technical University, Turkey while pursuing his \\
Ph. D studies. His research interests include \\
Electrification of Railway Systems, Renewable \\
Energy Systems and Smart Grid. \\
Huseyin AKDEMIR was born in Konya, \\
Turkey. He completed B.Sc. at the Department of \\
Electrical Engineering, Yildiz Technical \\
University in 2014. He is currently working as a \\
Research Assistant at the Electrical Engineering \\
Department of Yildiz Technical University, \\
Turkey while pursuing his M.Sc. studies. His \\
research interests include Renewable Energy \\
Systems, Protection of Power Sytems and \\
Lighting Technology. \\
\hline
\end{tabular}

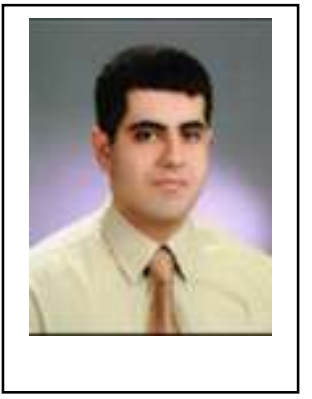

Bedri KEKEZOGLU was born in Istanbul, Turkey. He completed B.Sc., M.Sc., and PhD at the Department of Electrical Engineering department of Yildiz Technical University respectively in 2005, 2007, and 2013. He is currently working as an Assistant Professor at the Electrical Engineering Department of Yildiz Technical Universit ${ }^{-}$ include Power Syster Power Energy. 